\title{
CD14-dependent clearance of apoptotic cells by human macrophages: the role of phosphatidylserine
}

\author{
A Devitt ${ }^{1}$, S Pierce $^{2}$, C Oldreive ${ }^{1}$, WH Shingler ${ }^{1}$ \\ and CD Gregory ${ }^{*, 1}$ \\ 1 MRC Centre for Inflammation Research, University of Edinburgh, Edinburgh, \\ UK \\ 2 School of Biomedical Sciences, University of Nottingham Medical School, \\ Queen's Medical Centre, Nottingham, UK \\ * Corresponding author: CD Gregory, MRC Centre for Inflammation Research, \\ University of Edinburgh, 2nd Floor, Hugh Robson Building, George Square, \\ Edinburgh EH8 9XD, UK. Tel: +44 131 6511566; Fax: +44 131 6511848; \\ E-mail: chris.gregory@ed.ac.uk
}

Received 23.7.02; revised 23.9.02; accepted 3.10.02 Edited by M Piacentini

\section{Abstract}

Apoptotic-cell clearance is dependent on several macrophage surface molecules, including CD14. Phosphatidylserine (PS) becomes externalised during apoptosis and participates in the clearance process through its ability to bind to a novel receptor, PS-R. CD14 has the proven ability to bind phospholipids and may function as an alternative receptor for the externalised PS of apoptotic cells. Here we demonstrate that CD14 does not function preferentially as a PS receptor in apoptotic-cell clearance. Compared with phosphatidylcholine and phosphatidylethanolamine, PS was the least active phospholipid binding to human monocyte-derived macrophages and showed no specificity for soluble or membraneanchored CD14. Significantly, PS-containing liposomes failed to inhibit CD14-dependent uptake of apoptotic cells by macrophages. PS exposure was, however, found to be insufficient for either CD14-dependent or CD14-independent apoptotic-cell uptake by phagocytes. The additional features that enable apoptotic-cell clearance are derived from mechanisms that can be divorced temporally from those responsible for the morphological features of apoptosis.

Cell Death and Differentiation (2003) 10, 371-382. doi:10.1038/ sj.cdd. 4401168

Keywords: monocytes/macrophages; CD14; apoptosis; inflammation; phagocytosis; phosphatidylserine

Abbreviations: DAPI, 4,6-diamidino-2-phenylindole; HMDM, Human monocyte-derived macrophage; LS-RBC, lipidsymmetric erythrocytes; mCD14, membrane-anchored CD14; PC, phosphatidylcholine; PE, phosphatidylethanolamine; PMN, polymorphonuclear leukocyte; PS, phosphatidylserine; PS-R, novel PS receptor; sCD14, soluble CD14

\section{Introduction}

Cells undergoing apoptosis are normally efficiently phagocytosed in the absence of inflammation in vivo. The fate of apoptotic cells has important consequences for the control of immune and inflammatory responses and defective or aberrant apoptotic-cell clearance may be significant contributory factors in autoimmune disease pathogenesis. ${ }^{1,2}$

Although the details have not yet been worked out, the mechanisms underlying apoptotic-cell clearance appear to be highly complex involving integral phagocyte membrane receptors, apoptotic-cell surface ligands and intermediate molecules. It is well established that cell surfaces become altered as a result of apoptosis such that dying and dead cells can interact efficiently with phagocytes. Apoptosis engenders a loss of plasma-membrane phospholipid asymmetry such that the anionic phospholipid, phosphatidylserine (PS), becomes effectively exposed on the outer membrane leaflet where it functions in apoptotic-cell clearance. ${ }^{3-5}$ Additional changes, including ill-defined alterations in surface sugars ${ }^{6,7}$ and in ICAM- $3,{ }^{8}$ have also been shown to be involved in the clearance phase of the apoptosis programme, as has CD31, which was shown recently to endow viable, but not apoptotic cells, with repulsive signals affecting phagocytes. ${ }^{9}$ Phagocytes of apoptotic cells, the most frequently studied being macrophages, possess a battery of surface molecules that can be deployed for binding and uptake of apoptotic cells. These include CD14 ${ }^{10}$ and a novel PS receptor, the PS-R, ${ }^{11}$ together with the integrin $\alpha_{v} \beta_{3},{ }^{12,13}$ CD $36,{ }^{13,14}$ the class $A$ scavenger receptor SR-A, ${ }^{15}$ the ATP-binding cassette transporter, $A B C-1,{ }^{16,17}$ the receptor tyrosine kinase, MER ${ }^{18}$ and the $\alpha$-2-macroglobulin receptor, CD91. ${ }^{19}$ Additional intermediate factors including thrombospondin, ${ }^{13} \mathrm{C} 1 \mathrm{q},{ }^{19,20} \mathrm{C}$ reactive protein, ${ }^{21}$ collectins $^{19,22}$ and calreticulin ${ }^{19}$ may opsonise apoptotic cells or function in bridging macrophage and apoptotic-cell surfaces. The relationships between the apparently redundant clearance systems so far described have yet to be defined, although a two-signal, 'tether and tickle' mechanism has been proposed. ${ }^{23}$

It has been shown previously that engagement of PS by the PS-R is an essential prerequisite of apoptotic-cell engulfment. ${ }^{11,23}$ Whether the PS-R is the only PS-receptor that is functional in the phagocytosis of apoptotic cells is unclear at present. Work from our laboratory ${ }^{8,10,24}$ and elsewhere ${ }^{25}$ has shown that human and murine macrophages utilise plasma membrane-anchored CD14 (mCD14) in apoptotic-cell clearance. In view of CD14's established capacity to interact with phospholipids, ${ }^{26-29}$ we reasoned that CD14 might function as a PS-receptor for apoptotic cells. ${ }^{10}$ We now report, however, that CD14 does not function preferentially as a PS-receptor in apoptotic-cell clearance, supporting the PSR's principal role in this regard. Furthermore, in the course of this work, we were able to identify apoptotic leukocytes of various lineages that exposed PS at their surfaces, displayed 
classical morphological features of apoptosis, and yet were unable to interact efficiently with monocyte-derived macrophages in vitro. These apoptotic cells subsequently acquired, through cell-autonomous means, additional features that enabled their binding and phagocytosis through both CD14dependent and -independent mechanisms.

These results demonstrate firstly that PS is an unlikely candidate ligand of apoptotic cells for $\mathrm{mCD} 14$, and secondly that externalisation of PS is insufficient for apoptotic-cell clearance by human monocyte-derived macrophages (HMDM) in vitro. While identification of the additional features of apoptotic cells that are required for efficient phagocytosis is beyond the scope of the present investigations, it can be concluded that they are generated through biochemical mechanisms that can be uncoupled, at least temporally, from those responsible for the stereotypical morphological features of apoptosis.

\section{Results}

\section{PS exposure and capacity for CD14-dependent clearance are common features of apoptotic cells that are not consistently related}

In previous studies, we have demonstrated the involvement of macrophage CD14 in the clearance of apoptotic lymphocytes, neutrophils and embryonic kidney cells by HMDM. ${ }^{8,10,24}$ The results shown in Figure 1 confirm and extend these observations. Using the CD14-blocking mAb 61D3, we demonstrate that macrophage clearance of different lineages of apoptotic cells of human, murine and simian origin is dependent, to varying extents, on CD14 (Figure 1a). When annexin V was used to label the same panel of apoptosis-induced cells it was found that PS was exposed in all cases, but to varying degrees (Figure 1b). Furthermore, we found no consistent correlation between the amount of annexin- $V$ labelling and the capacity to interact with HMDM. For example, apoptotic (staurosporineinduced) Jurkat $T$ cells were labelled substantially by annexin $\mathrm{V}$, but only displayed low-level capacity to interact with macrophages (22\% for the cells shown (Figure 1b). By contrast, staurosporine-induced apoptotic A1.1 cells - which also labelled well with annexin $\mathrm{V}$ though to a lesser extent than Jurkats in the samples analysed (Figure 1b) - were able to interact significantly better with HMDM (79\%, Figure 1b). Therefore, while PS externalisation is a prominent and consistent feature of apoptosis that is paralleled by macrophage clearance, the degree of annexin- $V$ labelling of an apoptotic cell appears not to be directly coupled to its capacity to be engulfed by HMDM.

\section{PS-containing liposomes fail to bind preferentially to HMDM, or to cell-bound or soluble recombinant CD14}

In order to test the hypothesis that CD14 acts as a receptor for PS displayed on apoptotic cells, radiolabelled liposomes composed either of PC alone or in combination with PS (50:50) or PE (50:50) were assessed for their ability to bind to HMDM, or to recombinant plasma membrane-anchored or soluble CD14. Such PS-containing liposomes have been used previously to define the function of PS in apoptotic-cell phagocytosis. ${ }^{3,35}$ As shown in Figure 2a, while all liposome preparations bound very poorly to HMDM, PC liposomes always bound most effectively, while PS-containing liposomes bound least. When recombinant CD14 expressed on BJAB cells was analysed in the same way, no differences were demonstrable between CD14-negative and CD14-positive cells with any of the liposomes tested (Figure 2b), although PS-containing liposomes were more active than the PC-only and PE preparations. Similarly, when recombinant soluble CD14 (CD14-Fc) was compared with a control Fc fusion protein (ICAM-3-Fc), no significant specific binding to CD14 was observed with any of the liposome preparations (Figure 2c), although, again, PS-containing liposomes were the most active in binding. These results indicate that while CD14 can bind liposomes including those containing PS, it does so no more effectively than other receptors, including ICAM-3.

\section{CD14-dependent macrophage clearance of apoptotic cells can occur in the pre- sence of PS-containing liposomes that are active in inhibiting PS-dependent apopto- tic-cell clearance}

The activity of PS-receptors in the clearance process was defined originally as the specific inhibition of the engulfment of apoptotic cells by PS-containing liposomes that compete for PSreceptors. ${ }^{3,35}$ We used this approach to assess the activity of PS-receptors in clearance of apoptotic lymphocytes by HMDM. As shown in Figure 3, HMDM that interacted with apoptotic cells via CD14-dependent means (as judged by inhibition with 61D3 mAb) were not inhibited by PS-containing liposomes. The biological effectiveness of the liposome preparations was monitored using macrophages treated with $\beta$-glucan (Figure 3). Such macrophages were inhibited in their capacity to interact with apoptotic lymphocytes both by 61D3 and by PS-containing liposomes, though not by PC-only or PE-containing liposomes (Figure 3). These results indicate that, at least in the case of non-activated HMDM, CD14 is functional in apoptotic-cell clearance in the absence of demonstrable PS-receptor activity.

\section{Lipid-symmetric erythrocytes fail to affect apoptotic-cell clearance by monocyte-derived macrophages}

To investigate further the possible activity of PS-receptors in engulfment of apoptotic lymphocytes by HMDM, we assessed whether lipid-symmetric erythrocytes were able to inhibit the process. We reasoned that more sensitive definition of the activity of PS-receptors might be achieved through competition by PS exposed in a plasma-membrane context. As shown in Figure 4, lipid-symmetric erythrocytes failed to affect the interaction of apoptotic lymphocytes with HMDM (Figure 4a). Again, inhibition by 61D3 confirmed that the CD14-dependent pathway was active in these assays. Staining with annexin V was used to monitor the externalised PS of the lipid-symmetric erythrocytes. These results provide further evidence that HMDM engage in CD14-dependent apoptotic-cell clearance in the absence of demonstrable PS-receptor activity. 


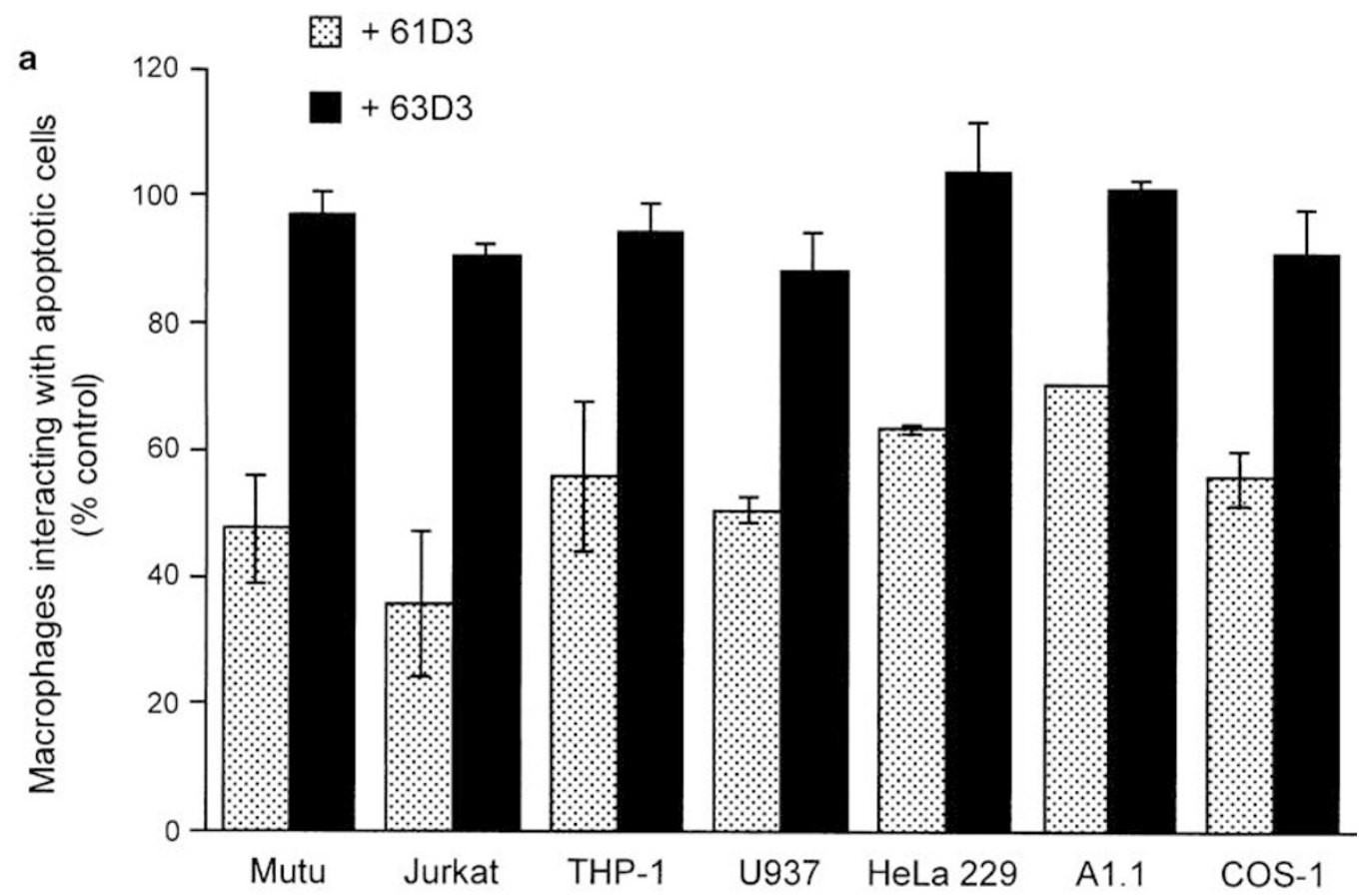

b

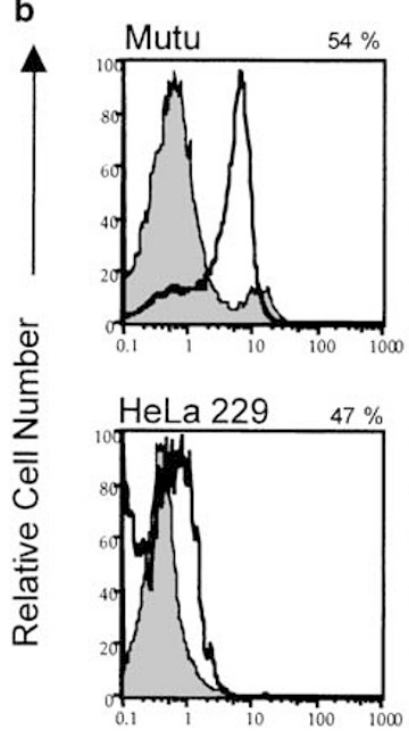

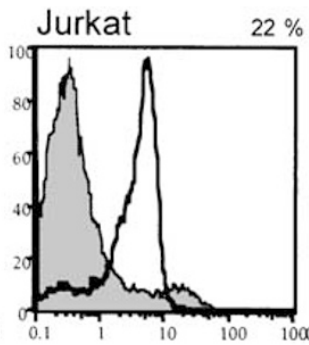

THP-1
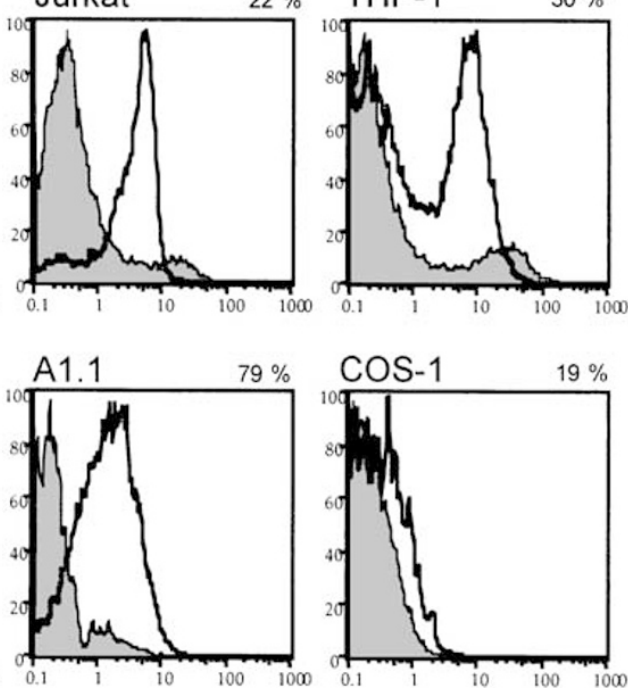

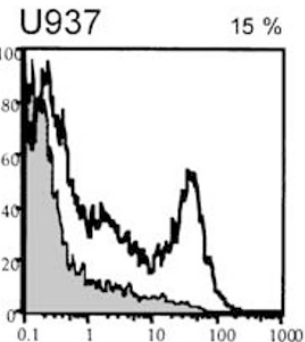

Annexin V-FITC

Figure 1 CD14-dependent interaction of various cell lineages with HMDM: relationship with PS exposure. (a) Cells were induced into apoptosis by culture for 16-20 $\mathrm{h}$ with ionomycin (Mutu), staurosporine (Jurkat, U937, A1.1) or etoposide (THP-1, Hela 229, COS-1) followed by co-culture with 7-day HMDM. The proportion of macrophages interacting with apoptotic target cells (binding and phagocytosing) in the presence or absence of the anti-CD14 mAbs 63D3 (blocker) or 63D3 (non-blocker) was subsequently assessed microscopically. Results with mAbs are normalised to the levels of interaction observed without mAbs. Results shown are means \pm S.D. of three to four separate experiments for each cell line. (b) Flow cytometric histograms (clear profiles) of annexin-V-FITC labelling of cell lines induced into apoptosis as described in (a). Grey histograms are overlaid to show annexin-V labelling of control, untreated cells. Representative results of three to four experiments. Percentages shown at the top right of each sample indicate the levels of macrophage interaction (HMDM in the absence of mAbs, as described in (a)) obtained with the induced cells for each experiment shown

\section{PS exposure is insufficient for clearance of apoptotic leukocytes by human macrophages in vitro}

To define further the relationship between PS exposure and CD14-dependent clearance of apoptotic cells by human macrophages, the abilities of populations of human leukocytes (1) to expose PS and (2) to interact with macrophages were assessed in parallel over time following treatment with apoptosis-inducing stimuli. As shown in Figure 5, PMNs were followed for a period of $12 \mathrm{~h}$ after induction of apoptosis using a single dose of UV radiation $\left(200 \mathrm{~mJ} \mathrm{~cm}^{-2}\right)$. Flow cytometric 

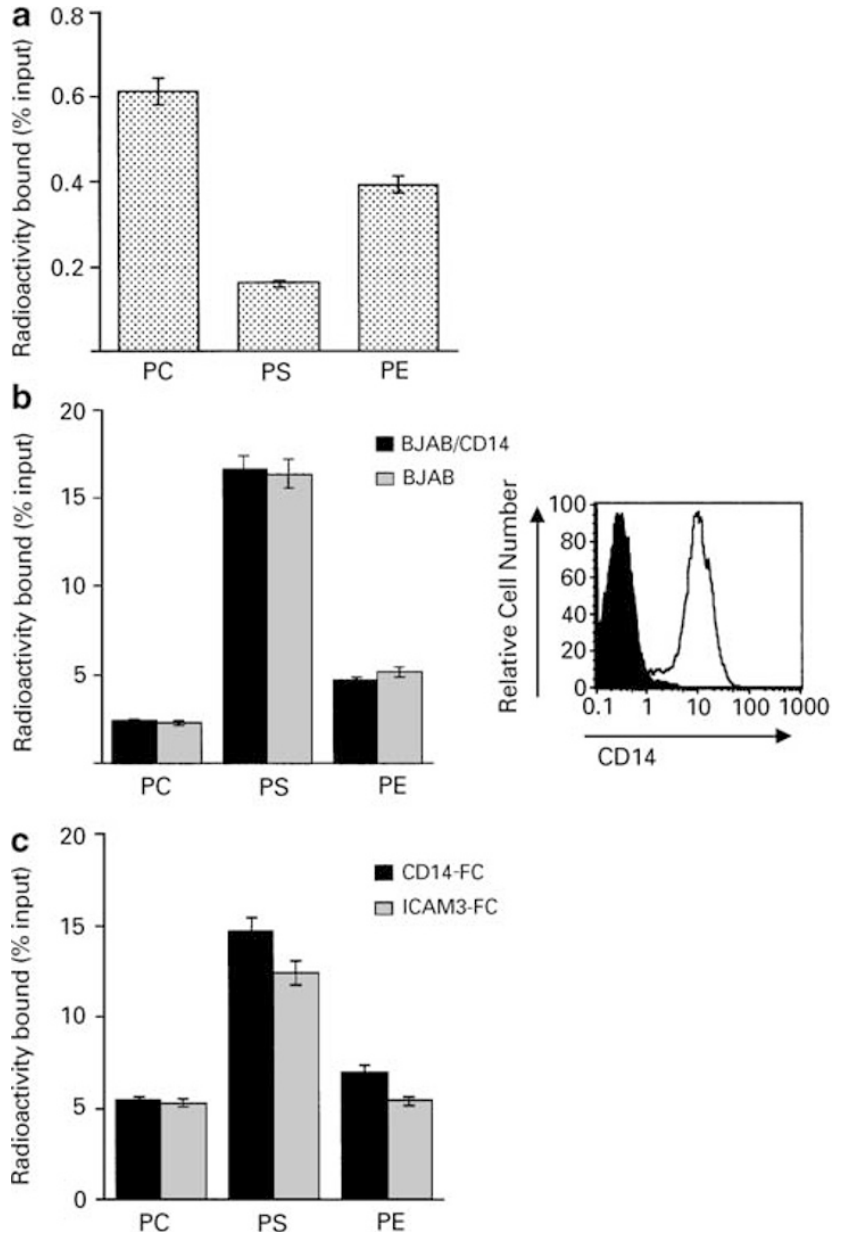

Figure 2 Liposome binding to HMDM and to $\mathrm{mCD} 14$ and SCD14. ${ }^{3} \mathrm{H}$-labelled liposome preparations constituted of either PC alone or together with PS or PE were assessed for their capacity to bind to 7-day HMDM (a), mCD14-negative and mCD14-positive BJAB cells (b) or soluble recombinant CD14 (CD14-Fc fusion protein) as compared with soluble recombinant ICAM-3-Fc (c). Results represent means \pm S.D. ( $n=3$ experiments) of bound radioactivity expressed as percentage input radioactivity. Right panel in (b) shows flow cytometric histograms of CD14 levels in BJAB cells transfected with empty vector (black) or CD14-containing vector assessed by indirect immunofluorescence staining using anti-CD14 mAb 63D3. Levels observed with empty vector were identical to background staining (not shown)

analysis revealed that by $7 \mathrm{~h}$ post-irradiation, the vast majority of the cells had become annexin-V-positive, PI-negative, with most achieving annexin- $V$ positivity within the first $4 \mathrm{~h}$ (Figure 5a). However, these cells failed to interact with HMDM beyond time-zero PMNs and showed no significant increase in this activity until $12 \mathrm{~h}$ after induction (Figure $5 \mathrm{~b}$ ). At this time, some annexin-V-positive cells were also PI-positive (Figure 5a) indicating loss of plasma-membrane integrity. Interaction of 12-h PMNs with macrophages was only marginally inhibited by 61D3 confirming previous observations ${ }^{24,33}$ that apoptotic PMNs appear relatively independent of the mCD14 clearance mechanism as assessed by CD14 mAb blockade.

Broadly, similar results were obtained with BL cells induced by UV irradiation. As shown in Figure 6a, PS exposure was rapidly demonstrable reaching around $50-60 \%$ between 5 and $8 \mathrm{~h}$ after induction. At these times the vast majority of the

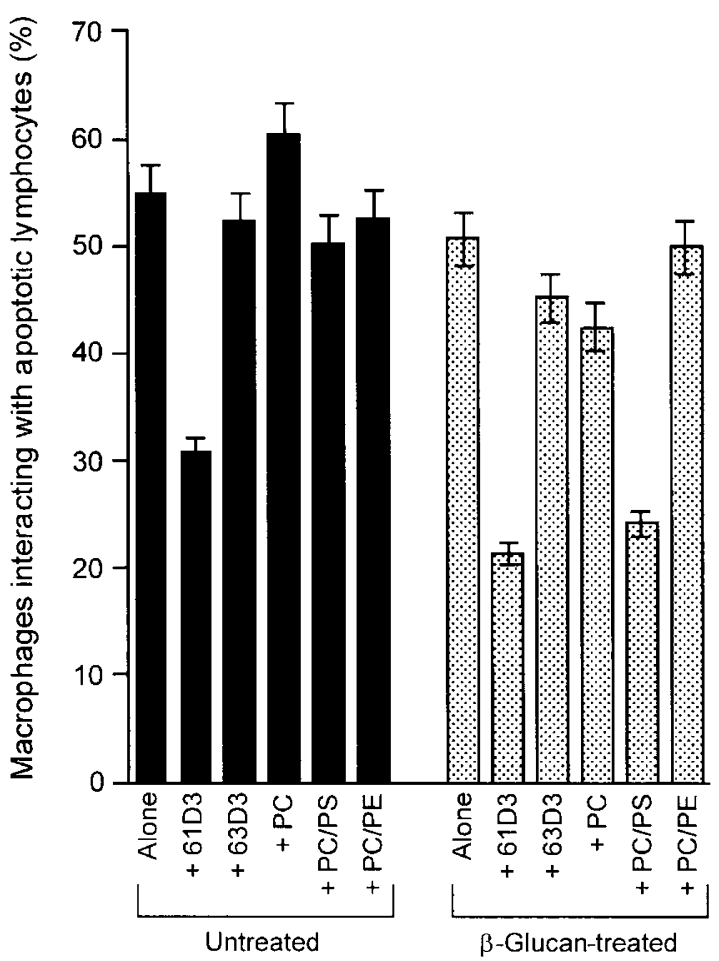

Figure 3 Inhibition of apoptotic-cell clearance by anti-CD14 mAb 61D3 compared with PS-containing liposomes. Untreated (black bars) or $\beta$-glucantreated HMDM (stippled bars) were assessed for their capacity to interact with apoptotic B lymphocytes (ionomycin-treated Mutu BL cells) in the presence or absence of the indicated anti-CD14 mAbs or liposomes. Data shown are means + S.D. of replicate samples from one experiment representative of three similar ones

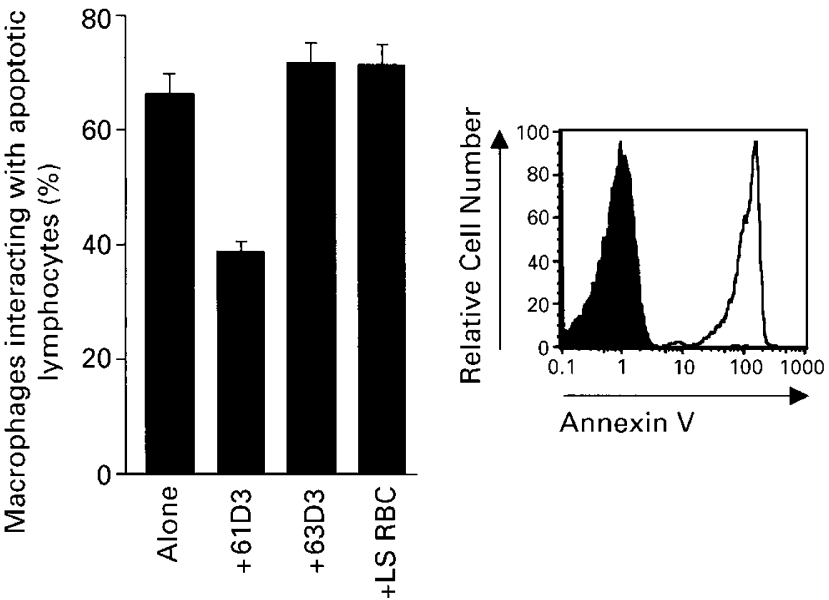

Figure 4 Effect of lipid-symmetric erythrocytes (LS-RBC) on apoptotic-cell clearance by HMDM. HMDM (7-day) were assessed for their capacity to interact with apoptotic B lymphocytes (ionomycin-treated Mutu BL cells) in the presence or absence of the indicated anti-CD14 mAbs or LS RBC. Data shown are means \pm S.D. of replicate samples from one experiment representative of three similar ones. Right panel: flow cytometric histograms of annexin-V-labelled normal erythrocytes (black) and LS-RBC to monitor PS exposure

cells excluded $\mathrm{PI}$, but after $8 \mathrm{~h}$, membrane integrity was rapidly lost and by $24 \mathrm{~h}$ the majority of the cells became $\mathrm{PI}$ positive (Figure 6a). Notably, most of the 24-h cells had become annexin- $\mathrm{V}^{\text {low }}$ or negative suggesting loss or mod- 
a

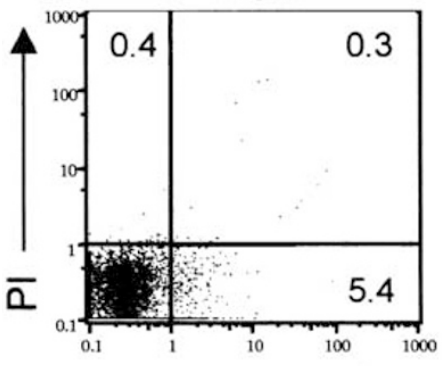

Annexin V-FITC
$4 h$

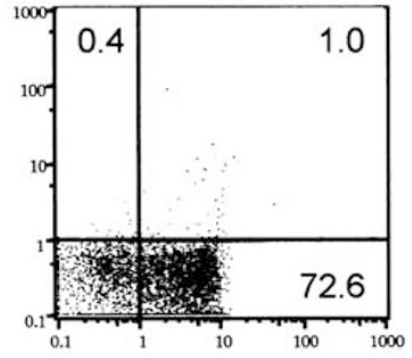

$7 \mathrm{~h}$

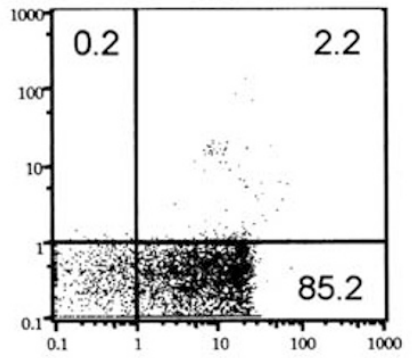

$12 \mathrm{~h}$

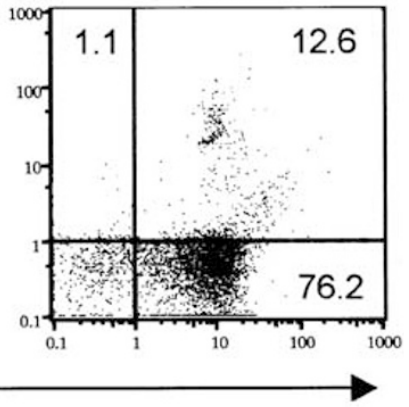

b

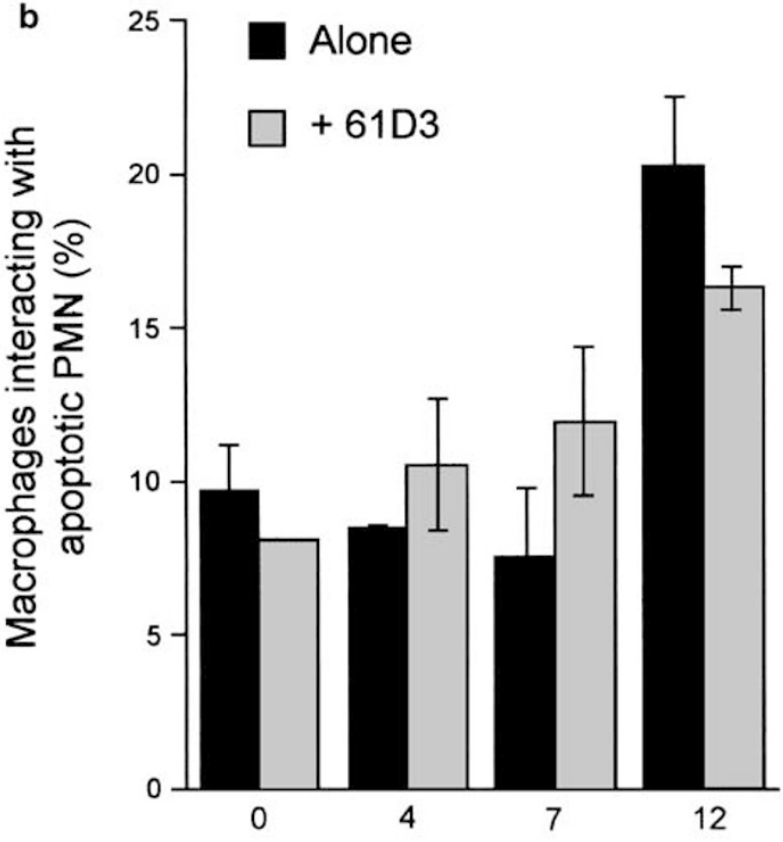

Hours after induction

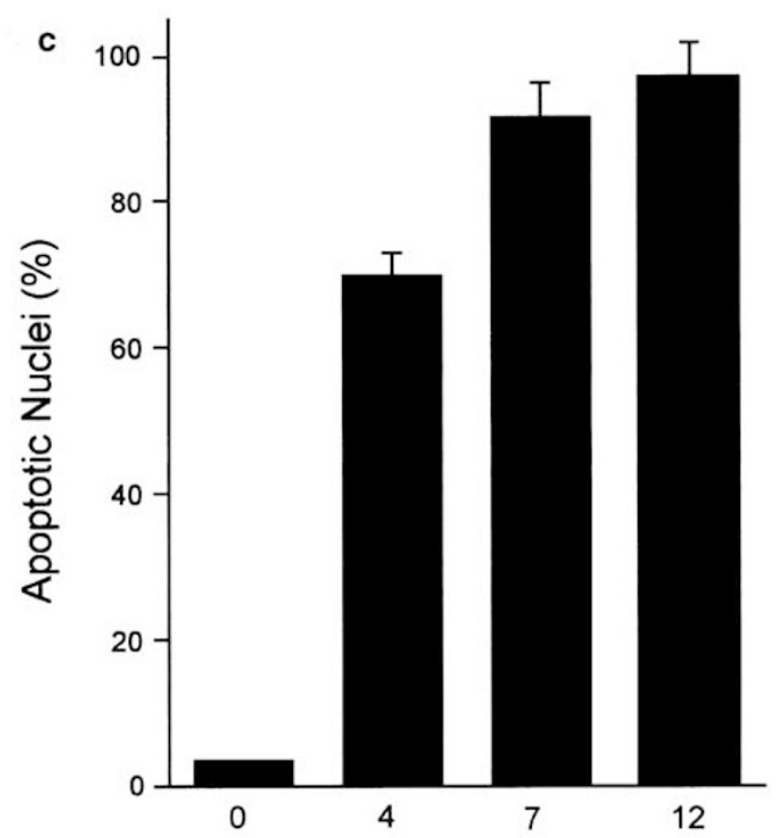

Hours after induction
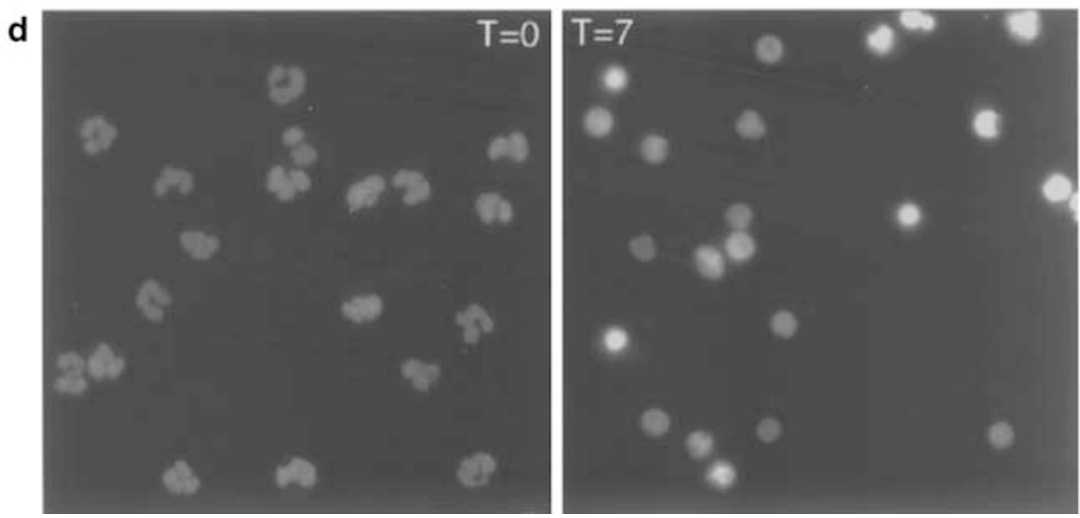

Figure 5 Time-course of induction of apoptosis and capacity of apoptotic neutrophils to interact with HMDM. Human PMN were induced to undergo apoptosis by UV treatment and at 0, 4,7 and $12 \mathrm{~h}$ after treatment were assessed in parallel for PS exposure (a), capacity to interact with 7-day HMDM in the presence or absence of mAb 61D3 (b), and morphological features of apoptosis assessed by DAPI staining (c, d). Results in (a) show flow cytometric dot plots of annexin V versus propidium iodide (PI) labelling. Figures demonstrate the proportion of events $(\%)$ measured in the indicated quadrants. All data shown are means + S.D. of replicate samples from one experiment representative of three similar ones. (d) Shows the typical morphological features of viable (polymorphic nucleus) and apoptotic (single bright nuclear 'spot') PMN at 0 and $7 \mathrm{~h}$ after treatment 
a

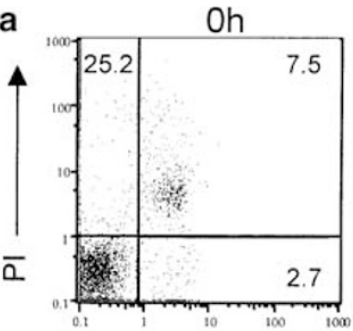

$2 \mathrm{~h}$

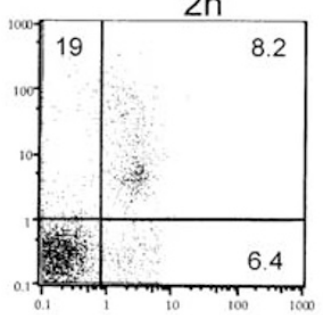

$5 \mathrm{~h}$

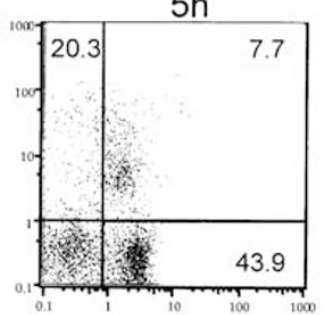

$8 \mathrm{~h}$

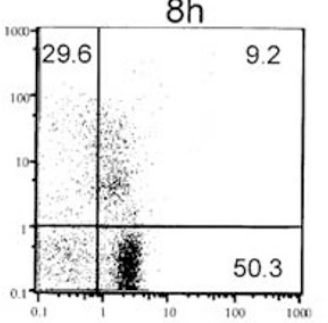

$24 \mathrm{~h}$

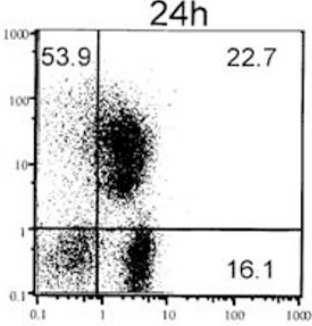

Annexin V-FITC
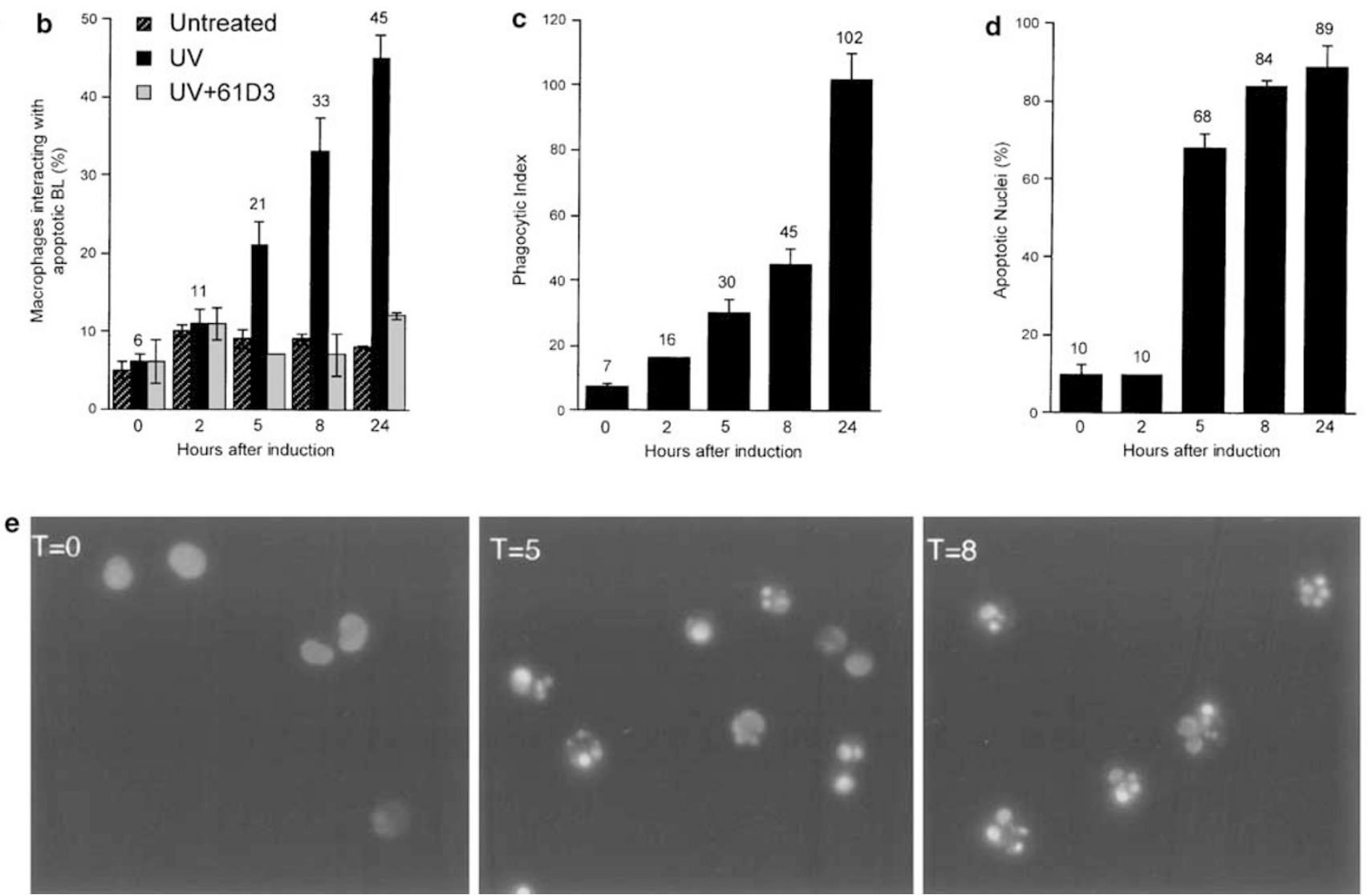

Figure 6 Time-course of induction of apoptosis and capacity of apoptotic BL cells to interact with HMDM. Mutu BL cells were induced to undergo apoptosis by UV treatment, and at 0, 2, 5, 8 and $24 \mathrm{~h}$ after treatment were assessed in parallel for PS exposure (a), capacity to interact with 7-day HMDM in the presence or absence of $\mathrm{mAb} 61 \mathrm{D} 3(\mathbf{b}, \mathbf{c})$, and morphological features of apoptosis assessed by DAPI staining (d, e). Results in (a) show flow cytometric dot plots of annexin $\mathrm{V}$ versus propidium iodide (PI) labelling. Figures in quadrants are as in Figure 5. For reference, figures in (b), (c) and (d) above black bars show actual values of interacting macrophages, Phagocytic Index and apoptotic nuclei, respectively. All data shown are means \pm S.D. of replicate samples from one experiment representative of five similar ones. (e) Shows the typical morphological features of viable (diffuse, regular nucleus) and apoptotic (polymorphic and fragmented nuclei) BL cells at 0,5 and $8 \mathrm{~h}$ after treatment

ification of PS such that annexin-V binding was inhibited. Figure $6 \mathrm{~b}$ shows the results of the same cells interacting with HMDM over the same time-course and indicates clear increases of interaction with induction time. Substantial CD14 dependence of all interactions was observed after 5 hours' induction. Between 2 and 5 hours' induction, the proportion of macrophages interacting with apoptotic BL cells had increased by only $10 \%$ (Figure $6 \mathrm{~b}$ ), while the proportion of annexin- $V$ binding cells had increased by almost $40 \%$ (Figure $6 a)$. By contrast, a further $12 \%$ increase in interacting macrophages between 5 and 8 hours' induction reflected approximately a $10 \%$ increase in annexin- $\mathrm{V}$ binding whereas another $12 \%$ increase in interacting macrophages between 8 and $24 \mathrm{~h}$ was paralleled by a decrease in overall annexin- $\mathrm{V}$ binding to the apoptotic cells. Phagocytic Index was used to monitor more closely the engulfment of apoptotic BL cells over time since it accounts for the number of engulfed cells per macrophage as well as the proportion of macrophages engulfing apoptotic cells. However, as shown in Figure 6c, Phagocytic Index also failed to correlate closely with annexin$\mathrm{V}$ binding to the target cells. Significantly, the highest Phagocytic Index (102, Figure 6c) was observed using 24-h cells, whereas cells at $8 \mathrm{~h}$ - the peak of annexin- $\mathrm{V}$ binding produced a Phagocytic Index by HMDM of only 45 . 
a

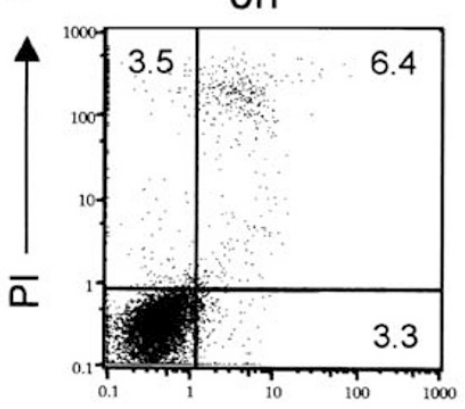

$8 \mathrm{~h}$

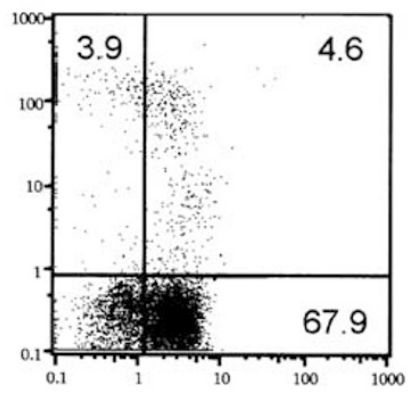

$16 \mathrm{~h}$

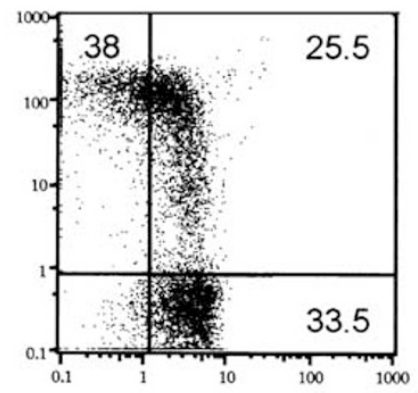

$24 \mathrm{~h}$

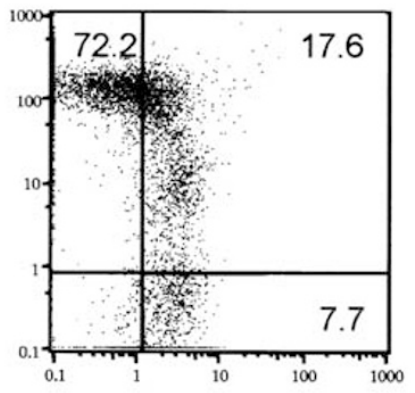

Annexin V-FITC
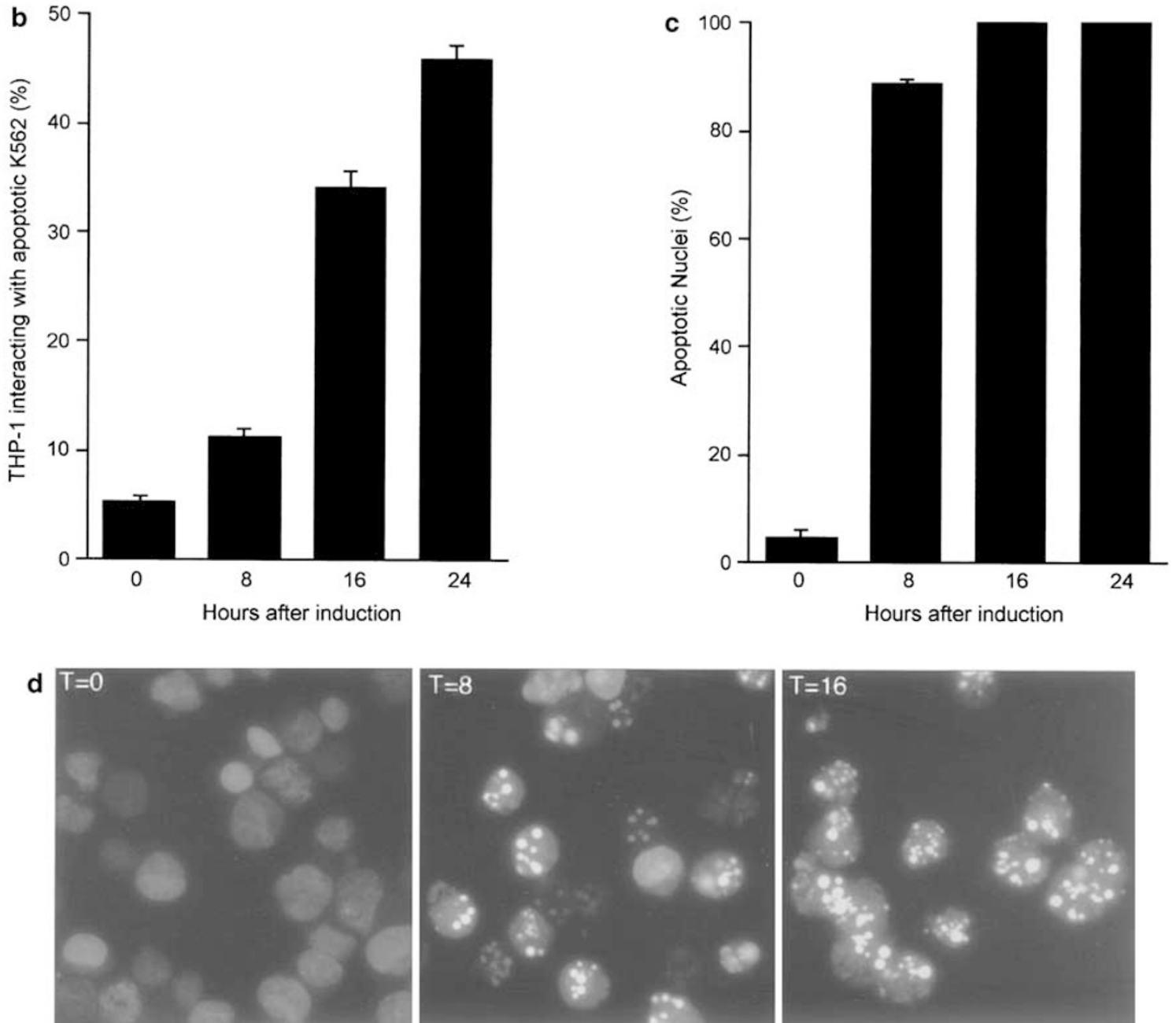

Figure 7 Time-course of induction of apoptosis and capacity of apoptotic K562 cells to interact with THP-1 'macrophages'. K562 cells were induced to undergo apoptosis by treatment with TRAIL in the presence of cycloheximide and at $0,8,16$ and $24 \mathrm{~h}$ after treatment were assessed in parallel for PS exposure (a), capacity to interact with THP-1 cells differentiated by vitamin $\mathrm{D}_{3} / \mathrm{TPA}$ treatment (b), and morphological features of apoptosis assessed by DAPI staining (c, d). Results in (a) show flow cytometric dot plots of annexin $\mathrm{V}$ versus propidium iodide $(\mathrm{PI})$ labelling. Figures in quadrants are as in Figure 5 . Assays in (b) were performed by flow cytometry. Photomicrographs of DAPI-stained cells in (d) show the classically condensed chromatin and fragmented nuclei of apoptotic cells following TRAIL induction. All data shown are means \pm S.D. of replicate samples from one experiment representative of four similar

Further observations were made using different apoptotic target cells (K562 erythroleukaemic cells), a different apoptosis-inducing stimulus (TRAIL) and different phagocytes (differentiated THP-1 cells). As shown in Figure 7, around
$70 \%$ of $\mathrm{K} 562$ cells could be labelled with annexin $\mathrm{V}$ within $8 \mathrm{~h}$ of TRAIL induction (Figure 7a). At this time, the vast majority of the annexin-V-positive cells excluded PI. However, it was not until $16 \mathrm{~h}$ after induction that these cells were capable of 
interacting substantially with THP-1 'macrophages' (Figure $7 b)$, by which time large proportions of the K562 population had become PI-positive and annexin- $\mathrm{V}^{\text {low }} /$ negative (Figure $7 a)$. By $24 \mathrm{~h}$, the capacity of the TRAIL-induced K562 cells to interact with THP-1 cells had increased further (Figure 7b), but the majority of the cells had become annexin- $V^{\text {low }} /$ negative (Figure 7a). These results show that, in all three systems tested, even though the majority of cells may externalise PS following induction of apoptosis, such plasma-membrane changes are insufficient to enable competent interaction of apoptotic cells with macrophages in vitro.

\section{Morphological characteristics of apoptosis can be acquired prior to features that permit efficient phagocytosis of apoptotic cells in vitro}

In the three systems tested above, apoptosis was monitored in the target leukocytes by fluorescence microscopy of nuclear morphology following DAPI staining (Figure $5 \mathrm{c}, \mathrm{d}$, $6 \mathrm{~d}$, e and $7 \mathrm{c}, \mathrm{d}$ ). These morphological analyses yielded an unexpected result: that major populations of classically apoptotic cells could be identified that were clearly unable to interact effectively with macrophages. Thus, as shown in Figure 5, even though a large proportion of the PMNs were apoptotic at 4 and $7 \mathrm{~h}$ after induction (Figure 5c, d), few were engulfed by HMDMs at these times (Figure 5b). Similarly, as shown in Figure 6, interaction of BL cells with HMDM was relatively inefficient at $5 \mathrm{~h}$ after induction of apoptosis (Figure $6 \mathrm{~b}, \mathrm{c}$ ) even though at this time almost $70 \%$ of the cells were morphologically apoptotic (Figure 6d). By $8 \mathrm{~h}$, the cells were maximally apoptotic by morphological criteria (Figure 6d), but were only recognised efficiently at $24 \mathrm{~h}$ (Figure $6 \mathrm{~b}, \mathrm{c}$ ). Similar observations were made with $\mathrm{K} 562$, which approached maximum levels of morphological apoptosis by $8 \mathrm{~h}$ after induction by TRAIL (Figure 7c, d). At this time only low levels of interaction with THP-1 phagocytes could be measured (Figure 7b).

Without exception, continued culture of apoptotic cells resulted in their acquisition of additional features that enabled more efficient interaction with macrophages (Figure 5b, 6b, c, $7 b)$. The capacity to interact with macrophages was acquired with the same kinetics as loss of plasma-membrane integrity (Figure 5a, b, 6a-c, 7a, b). This suggests that the capacity of apoptotic cells to be engulfed in the present assays is gained at a relatively late stage in the apoptosis programme. Furthermore, the results show that the molecular mechanisms responsible not only for the exposure of PS, but also for the nuclear morphological features of apoptosis are insufficient to enable macrophage engulfment.

\section{Discussion}

The present work was initiated to clarify possible relationships between CD14- and PS-dependent apoptotic-cell clearance mechanisms. Growing evidence that CD14, an established macrophage receptor of apoptotic cells, ${ }^{10,25}$ can bind PS, a plasma-membrane phospholipid that becomes externalised during apoptosis, ${ }^{3}$ provided an important impetus for these investigations. While the work that established CD14 as a phospholipid receptor (and indeed phospholipid transfer protein) used the soluble form of CD14 (sCD14), ${ }^{26}$ which has yet to be proven active in apoptotic-cell clearance, it is now known that both sCD14 and mCD14 can bind phospholipids, including PS. ${ }^{27-29}$ We analysed the selectivity of binding of PS-containing liposomes to sCD14 or mCD14. We also investigated the function of $\mathrm{mCD} 14$ on macrophages (human monocyte-derived, HMDM), which have been reported previously to engulf apoptotic cells via mechanisms that are not preferentially biased towards the activity of receptors for PS as assessed by the inhibitory effects of PScontaining liposomes. ${ }^{35}$ We found that many different cell types engaged in apoptosis triggered by a variety of stimuli could interact with HMDM through CD14-dependent means. The involvement of CD14, however, did not correlate closely with the levels of PS exposed (annexin-V positivity, Figure 1). Liposome-binding studies revealed that, while PS can undoubtedly bind BJAB transfectants overexpressing mCD14 and soluble CD14-Fc, this binding is not CD14specific since PS-containing liposomes also bound with comparable efficiency both to CD14-negative cells and to ICAM-3-Fc (Figure 2). It remains possible that PS-containing liposomes bind effectively both to CD14 and to ICAM-3 (since BJAB cells express ICAM-3 - not shown). Since both molecules have been implicated in apoptotic-leukocyte clearance by HMDM - CD14 on the macrophage and ICAM3 on the apoptotic cell ${ }^{8}-$ it is conceivable that bodies on which PS is exposed (e.g. apoptotic-cell blebs) could physically bridge apoptotic cells and macrophages, thereby allowing CD14 to function as a PS-receptor.

Significantly, PS-containing liposomes were unable to inhibit apoptotic-cell clearance by HMDM under conditions in which CD14 was active, as judged by anti-CD14 mAb inhibition (Figure 3). Taken together, these results indicate that CD14 is unlikely to bind preferentially to apoptotic-cellassociated PS and fails to function as a PS-receptor on HMDMs. It remains theoretically possible that $\mathrm{mCD} 14$ is active as a PS-receptor on $\beta$-glucan-treated HMDMs since these macrophages have demonstrable PS-receptor activity, as judged by the capacity of PS liposomes to inhibit apoptoticcell engulfment ${ }^{33}$ (Figure 3 ). It is also conceivable that CD14 could function as a PS-R of nonactivated HMDM that required access to PS in a more physiological context than that of PSloaded liposomes. This seems improbable, given the inability of lipid-symmetric erythrocytes, which display PS in the context of a plasma membrane, to inhibit apoptotic-cell clearance by HMDM (Figure 4).

The results presented here argue strongly that $\mathrm{mCD} 14$ does not share functional activity with the PS-R that has been elegantly described by Fadok et al. $^{11}$ in binding PS to effect apoptotic-cell engulfment. It remains a possibility that other phospholipids are active as CD14 ligands, especially since PS has a relatively low affinity among phospholipids for CD14. ${ }^{27,29}$ CD14, however, has the known ability to interact with a wide range of biologically active molecules encompassing lipids, proteins and carbohydrates, ${ }^{36-38}$ and may prove to engage a diverse range of ligands in order to mediate apoptotic-cell clearance. The elucidation of such CD14 ligand(s) will be crucial in furthering current understanding of CD14's role in the removal of apoptotic cells. 
A constructive model of apoptotic-cell clearance has recently been proposed in which two signals, 'tether and tickle' are required for the full biological response of the phagocyte towards the apoptotic cell: engulfment accompanied by anti-inflammatory signal transduction. ${ }^{23}$ The evidence to date suggests that a multitude of molecules, including CD14, function in tethering apoptotic cells to phagocytes (signal one) and that a second signal is provided by PS interacting with the PS-R. ${ }^{23}$ Our results from the present as well as previous studies ${ }^{10}$ are consistent with the view that CD14 serves a tethering function in interacting with apoptotic cells. We were intrigued, however, by our findings (Figures 57) that apoptotic cells appear to acquire the capacity to interact with HMDM - through CD14-independent as well as CD14-dependent mechanisms - at a relatively late stage in the apoptotic process, hours after exposure of PS and the acquisition of apoptotic nuclear features. These observations were made in three different target cell types, two different apoptosis stimuli and two different human macrophage sources - primary HMDM and differentiated THP-1 cells. This would suggest that the capacity of apoptotic cells to interact with human macrophages can generally be uncoupled, at least temporally, from the mechanisms governing PS-exposure and morphological change during apoptosis. These results are in accordance with published work indicating that the stereotypical morphological features of the apoptotic nucleus derive from caspase-3 activation, whereas PS exposure results from mechanisms that are independent of caspase-3. ${ }^{39-42}$

Whether the PS-R described by Fadok et al. ${ }^{11}$ is functional in the engulfment of unstimulated HMDM is not yet clear. These phagocytes express only low levels of PS-R and activity of this receptor in apoptotic-cell clearance by HMDM cannot be demonstrated using either PS-containing liposomes ${ }^{35}$ (Figure 3) or anti-PS-R mAb blockade. ${ }^{11}$ However, it has been shown that engulfment of anti-CD36-tethered erythrocytes by HMDM can be induced by PS and inhibited by anti-PS-R mAb, ${ }^{23}$ indicating that unstimulated HMDM do indeed have functional PS-R. The data presented here are consistent with the view that PS-R, rather than CD14, is the most likely PS-receptor of apoptotic cells on HMDM.

Current evidence indicates that PS exposure is a necessary prerequisite to the efficient engulfment of apoptotic cells both by amateur and by professional phagocytes. ${ }^{5,43}$ Some studies have implied that PS exposure may also be sufficient for apoptotic-cell engulfment, ${ }^{5,44,45}$ and indeed it has been concluded that any additional features of apoptotic-cell membranes that may be required for engulfment become available immediately following PS externalisation. ${ }^{45}$ Artificial 'loading' of viable-cell surfaces with PS using PS-containing liposomes or $\mathrm{N}$-ethylmaleimide treatment has shown that the capacity of cells to be phagocytosed either by murine macrophages ${ }^{5,44}$ or by fibroblasts ${ }^{5}$ can be uncoupled from apoptosis. However, efficiencies of phagocytosis were relatively low in these studies and the mode of manipulation of the cells could have generated additional surface changes. Thus, it is unlikely that the effects of $\mathrm{N}$-ethylmaleimide treatment are limited to phospholipids and PS loading may incur additional alterations in membrane conformation that are required for engulfment. In addition, different populations of phagocytes may have different requirements of the apoptotic-cell membrane. Our results showing that features subsequent to PS exposure are required for efficient binding and phagocytosis of apoptotic cells support the contention that while PS exposure may be necessary for apoptotic-cell clearance, it is not sufficient. Indeed, PS itself may require modification in order to perform effectively at the apoptotic-cell surface. ${ }^{46}$ The requirement for specific additional features of dying cells would militate against inappropriate engulfment of cells - B lymphocytes for example ${ }^{47}$ - that expose PS for reasons unrelated to cell death. Further studies will be required to determine to what extent the defined additional features of dying cells are required by non-macrophage phagocytes such as 'amateur' phagocytic neighbours in solid tissues and immature dendritic cells.

It will be important to identify, in molecular terms, the additional features that must be acquired by apoptotic cells to enable their efficient phagocytosis by HMDM (and other phagocytes, as appropriate). Phospholipids apart, little is known about cell-surface changes that occur as a consequence of apoptosis, although changes in cell-surface carbohydrates $^{48,49}$ and modification of ICAM- $3^{8}$ are known to occur at apoptotic-cell surfaces and to contribute to phagocytic clearance. The antigen identified by the $\mathrm{PH} 2$ antibody is also involved in the clearance of late apoptotic cells. ${ }^{50}$ Furthermore, oxidation of molecules other than PS may be required to enhance apoptotic-cell clearance. ${ }^{51}$ It has also been shown recently that loss of repulsive mechanisms involving CD31 are required for interactions between apoptotic cells and phagocytes. ${ }^{9}$ While we have not sought in the present studies to identify definitive cell-surface characteristics that allow HMDM to interact efficiently with apoptotic cells, our results demonstrate that the cell-autonomous changes (Figures 5b, 6b, 7b) to permit clearance under serum-free conditions occur late in the apoptosis programme. These changes coincide, in our hands, with events that lead to plasma-membrane disruption, as measured by inclusion of propidium iodide (Figures 5a, 6a, 7a) though less marked differences between the uptake of early and late apoptotic neutrophils by HMDM have been reported recently. ${ }^{52}$ We did not address the question of whether the HMDM assay selectively measures the uptake of intact, late-apoptotic or of secondarily necrotic (leaky apoptotic) cells, or both populations. Whatever the case, we conclude that the ability of HMDM to undertake apoptotic-cell clearance under serumfree conditions is focussed on mechanisms that selectively target late-apoptotic or secondarily necrotic cells. These may be either CD14-dependent or CD14-independent mechanisms. More importantly, our results suggest that mechanisms that are thought to operate effectively in vivo to remove apoptotic cells at early stages in the programme are nonfunctional under the conditions studied. An obvious possibility is that established mechanisms that enhance apoptotic-cell clearance through plasma-borne factors such as collectins and $\mathrm{C} 1 \mathrm{q}$ by $\mathrm{HMDM}^{19}$ selectively enhance the engulfment of early stage apoptotic cells. Clearly, any role for plasma-borne factors may be relevant in vivo only to the clearance of dying cells in the circulation if such factors are absent from solid tissue sites. We are currently pursuing the role of exogenous soluble factors in enhancing the uptake of such cells by CD14- 
dependent means. Given the capacity of cells to repel phagocytes in order to avoid engulfment ${ }^{9}$ it will also be important to determine within the current models precisely when that repulsive activity is lost.

In conclusion, these studies demonstrate that PS (1) is unlikely to function as a major CD14 ligand in apoptotic-cell clearance, and (2) is wholly insufficient for apoptotic-cell clearance by human macrophages displaying active CD14dependent, as well as CD14-independent clearance capabilities. As yet, there is no evidence that apoptotic-cell engulfment can proceed in the absence of PS exposure. The results presented here are consistent with the view that loss of plasma-membrane asymmetry during apoptosis may serve at least two functions. One is exposure of PS, which permits ligation of PS-receptors on phagocytes, notably PSreceptor. Another is to provide the appropriate plasmamembrane context for additional changes that are required for efficient phagocytosis and that involve other phagocyte receptors, including CD14. Finally, our results also indicate that assessment of apoptotic-cell clearance in vitro may often be focussed on relatively late events that occur well beyond PS exposure and after the morphological hallmarks of apoptosis. The late-phase apoptotic-cell clearance pathways described here are likely to be represented among several others that cooperate to ensure the normally efficient phagocytosis of cells undergoing apoptosis in vivo.

\section{Materials and Methods}

\section{Cell isolation, cell lines and culture}

Peripheral blood PMN were isolated from citrated blood from normal volunteers by dextran sedimentation and centrifugation on Percoll as described. $^{30}$ Monocytes were isolated from defibrinated blood ${ }^{24}$ and cultured for 7 days in IMDM (Invitrogen Corp., Paisley, UK) containing 10\% autologous serum on glass slides or multiwell plates as described previously. ${ }^{10,19}$ Mutu I Burkitt's lymphoma (BL) cells, ${ }^{31}$ BJAB (human B), K562 (human erythroleukaemia), Jurkat (human T), THP-1 (human myelomonocytic), U937 (human myelomonocytic) and A1.1 (murine T), cells were cultured continuously in RPMl 1640 medium containing $2 \mathrm{mM} \mathrm{L-}$ glutamine supplemented with 10\% Serum Supreme (BioWhittaker, Wokingham, UK), $100 \mathrm{IU} / \mathrm{ml}$ penicillin and $100 \mu \mathrm{g} / \mathrm{ml}$ streptomycin. HeLa 229 (human epithelial) and COS-1 (simian epithelial) cells were cultured similarly, but in DMEM (Invitrogen Corp., Paisley, UK). CD14-expressing BJAB cells were prepared by transfection by electroporation of pEFMC1neop $\mathrm{A}^{32}$ containing human $C D 14$ followed by selection using G418. Control transfectants were prepared using pEFMC1neopA with $C D 14$ in reverse orientation. CD14 expression was monitored by immunofluorescence staining using the anti-CD14 mAb 63D3 followed by flow cytometric analysis.

\section{Apoptosis induction and quantification}

$\mathrm{PMN}$ or BL cells were subjected to UV-B irradiation to induce apoptosis. $\mathrm{BL}$ cells resuspended in RPMI containing 10\% Serum Supreme received $100 \mathrm{~mJ} / \mathrm{cm}^{2}$; PMN were resuspended in 0.2\% BSA/RPMI 1640, exposed to UV-B $\left(200 \mathrm{~mJ} / \mathrm{cm}^{2}\right)$ and subsequently rotated at $37^{\circ} \mathrm{C}$ for the indicated times. BL cells were also induced using ionomycin (Sigma, $1 \mu \mathrm{g} / \mathrm{ml}, 18 \mathrm{~h}$ ) as described. ${ }^{24} \mathrm{~K} 562$ cells in RPMI containing $10 \%$ Serum Supreme were induced to undergo apoptosis with TRAIL (BioMol, Plymouth Meeting, PA,
USA, $125 \mathrm{ng} / \mathrm{ml}$ ) in the presence of cycloheximide (Sigma, Poole, UK, $10 \mu \mathrm{g} / \mathrm{ml})$. Apoptosis was induced in other cells using either etoposide (Sigma, $100-850 \mu \mathrm{M}$ ) or staurosporine (Sigma, $1 \mu \mathrm{M}$ ) as indicated. For analysis of apoptotic nuclear morphology, cells were fixed in $1 \%$ formaldehyde, stained with 4,6-diamidino-2-phenylindole (DAPI, Sigma, $250 \mathrm{ng} / \mathrm{ml}$ ) and observed using a Zeiss Axioskop 2 fluorescence microscope (Carl Zeiss Ltd., Welwyn Garden City, UK). For quantitative analyses, percentages of apoptotic cells per $\geqslant 200$ macrophages counted per sample were enumerated.

\section{Annexin-V labelling and flow cytometry}

Cells were stained with annexin V-FITC (BioWhittaker) according to the manufacturer's instructions. Briefly, cells were washed and resuspended in binding buffer ( $10 \mathrm{mM} \mathrm{HEPES}, 150 \mathrm{mM} \mathrm{NaCl}, 2.5 \mathrm{mM} \mathrm{CaCl}_{2}$ ) containing annexin V-FITC (1:200 dilution in $200 \mu$ l per 200000 cells) for 2 min on ice. Cells were diluted to $1 \mathrm{ml}$ with binding buffer and Propidium iodide (PI) was added to a final concentration of $20 \mu \mathrm{g} / \mathrm{ml}$. Samples were analysed immediately on the Coulter XL flow cytometer (Beckman Coulter, Fullerton, CA, USA).

\section{Assays of macrophage interaction with apoptotic cells}

Assay of interaction (binding and phagocytosis) of HMDM with apoptotic cells was carried out either on multiwell glass slides ${ }^{10}$ or in 24 -well plates ${ }^{19}$ as described. Briefly, for the slide-based assay, macrophages and apoptotic cells $\left(10^{6}\right.$ per well) were co-cultured for $1 \mathrm{~h}$ at $37^{\circ} \mathrm{C}$ in RPMl containing $0.2 \%(\mathrm{w} / \mathrm{v})$ bovine serum albumin (Sigma). Unbound cells were removed by extensive washing and slides were fixed in methanol, stained with Jenner/Giemsa (BDH) and mounted in DePeX (BDH) prior to examination by light microscopy. Assays were performed similarly in 24well plates, but at the end of the procedure, cells were fixed in $1 \%$ formaldehyde and stained with Diff-Quik II (Dade Diagnostika Gmbh, D80807 Munich). In all cases, at least 200 macrophages were assessed in each of the duplicate wells. As appropriate, anti-CD14 mAbs 61D3 and 63D3 were included at a 1:100 dilution of ascitic fluid, liposomes were added $(10 \% \mathrm{v} / \mathrm{v})$ and erythrocytes were included at $10^{7}$ per slide well. For some experiments, macrophages were treated with $\beta$-glucan $\left(25 \mu \mathrm{g} / \mathrm{ml}^{-1}\right.$, Sigma) for $48 \mathrm{~h}$ prior to the assay. Data are presented either as percent macrophages interacting with apoptotic cells or as Phagocytic Index calculated as the percentage of phagocytosing macrophages $\times$ the average number of apoptotic cells engulfed per macrophage. ${ }^{33}$

For some experiments, THP-1 cells were used as the macrophage source. Cells were labelled using the fluorescent dye PKH26 (Sigma, $4 \mu \mathrm{M}$ ) for $5 \mathrm{~min}$, washed 3 times and cultured for $72 \mathrm{~h}$ in the presence of dihydroxy-1 Vitamin $D_{3}$ (a kind gift from Dr. Lise Binderup, Leo Pharmaceuticals, Ballerup, Denmark, $100 \mathrm{nM}$ ) and TPA (Sigma, $250 \mathrm{nM}$ ) in 48-well plates. Target K562 cells were labelled with Cell Tracker green (CMFDA, Molecular Probes, Eugene, OR, USA, $1 \mu \mathrm{M}$, $15 \mathrm{~min}$ ), washed 3 times and then induced to undergo apoptosis. THP-1 interaction was carried out in serum-free conditions as described for HMDM assays above. Induced K562 cells $\left(5 \times 10^{5}\right)$ were added to each well of THP-1 cells in $400 \mu \mathrm{l}$. After $1 \mathrm{~h}$ at $37^{\circ} \mathrm{C}$, wells were washed once to remove the majority of unbound cells and $200 \mu$ warmed trypsin/EDTA solution (Invitrogen) added. Cold RPMI containing 10\% Serum Supreme $(300 \mu l)$ was subsequently added and cells were lifted into suspension by gentle pipetting. Analyses were carried out on the flow cytometer. THP-1 cells, gated according to light-scatter properties and red PKH26 
fluorescence, were assessed for CMFDA (K562) fluorescence and results expressed as THP-1 cells interacting with K562 (\%).

\section{Liposome preparation and binding}

Liposomes were prepared according to established methods. $L-\alpha-$ phosphatidyl-L-serine (Sigma) or L- $\alpha$-phosphatidylethanolamine (Sigma), or mixed in varying proportions with $L-\alpha-$-phosphatidylcholine (Sigma) in chloroform at $0.1 \mathrm{mM}$. Following evaporation of solvent under nitrogen, liposomes were formed in RPMI 1640 medium using a sonicating bath (Decon, Ultrasonic Ltd). The liposomes were vortex mixed and left at room temperature for $2 \mathrm{~h}$ before use. Radiolabelled liposomes were prepared by incorporation of L-3-Phosphatidyl ( $\mathrm{N}$-methyl ${ }^{3} \mathrm{H}$ ) choline 1,2 dipalmitoyl ( $5 \mu \mathrm{Ci} / \mathrm{ml}$, Amersham, Life Science) prior to solvent extraction. Binding of radiolabelled liposomes to $\mathrm{HMDM}$ or BJAB cells was assessed after incubation for $60 \mathrm{~min}$ at $37^{\circ} \mathrm{C}$ and extensive washing with PBS. Cells were lysed in $200 \mu \mathrm{l}$ PBS containing $2 \%$ SDS and $100 \mu \mathrm{l}$ aliquots were subjected to liquid scintillation counting. Binding of liposomes to soluble recombinant CD14 was carried out in 96-well ELISA plates. Results of cell and protein binding assays are expressed as \% input radiolabel calculated as: (DPM of extract total/DPM of input liposomes) $\times 100$.

\section{Preparation of lipid-symmetric erythrocytes}

The method used was modified from Schlegel and Rechsteiner. ${ }^{34}$ Erythrocytes from heparinised blood were washed 5 times with $0.15 \mathrm{M}$ saline and resuspended in an equal volume of Hanks' balanced salts solution (HBSS; Life Technologies). To swell the erythrocytes, $200 \mu \mathrm{l}$ of the suspension was added to a hypotonic buffer made up of $5 \mathrm{ml}$ of distilled water and $6 \mathrm{ml}$ of HBSS. The suspension was then centrifuged at $5^{\circ} \mathrm{C}$ to produce a pellet of swollen erythrocytes. The supernatant was removed and $800 \mu \mathrm{l}$ of $10 \mathrm{mM}$ Tris, $\mathrm{pH} 7.4$ containing $1 \mathrm{mM} \mathrm{CaCl}_{2}$ was added to the pellet with gentle mixing, allowing the erythrocytes to be loaded with $\mathrm{Ca}^{2+}$. The erythrocytes were then placed on ice for $4 \mathrm{~min}$ after which time $60 \mu$ l of HBSS ( $10 \times$ concentration) was added with vortex mixing to shrink the cells. Following this the erythrocytes were incubated at $37^{\circ} \mathrm{C}$ in a water bath for $60 \mathrm{~min}$ and then gently washed twice in HBSS.

\section{Acknowledgments}

We are most grateful to Dr. Lise Binderup, Leo Pharmaceuticals for the generous gift of vitamin $D_{3}$. We thank Dr. Carol Anne Ogden for helpful discussion, Chandra Raykundalia for technical assistance and Heather Chisholm for expert secretarial support. This work was supported by the Medical Research Council (UK).

\section{References}

1. Savill J and Fadok V (2000) Corpse clearance defines the meaning of cell death. Nature 407: 784-788

2. Fadok VA, Bratton DL and Henson PM (2001) Phagocyte receptors for apoptotic cells: recognition, uptake, and consequences. J. Clin. Invest. 108: 957-962

3. Fadok VA, Voelker DR, Campbell PA, Cohen JJ, Bratton DL and Henson PM (1992) Exposure of phosphatidylserine on the surface of apoptotic lymphocytes triggers specific recognition and removal by macrophages. J. Immunol. 148: 2207-2216

4. Verhoven B, Schlegel RA and Williamson P (1995) Mechanisms of phosphatidylserine exposure, a phagocyte recognition signal, on apoptotic $T$ lymphocytes. J. Exp. Med. 182: 1597-1601
5. Fadok VA, de Cathelineau A, Daleke DL, Henson PM and Bratton DL (2001) Loss of phospholipid asymmetry and surface exposure of phosphatidylserine is required for phagocytosis of apoptotic cells by macrophages and fibroblasts. J. Biol. Chem. 276: 1071-1077

6. Duvall E, Wyllie AH and Morris RG (1985) Macrophage recognition of cells undergoing programmed cell death (apoptosis). Immunology 56: 351-358

7. Dini L, Autuori F, Lentini A, Oliverio S and Piacentini M (1992) The clearance of apoptotic cells in the liver is mediated by the asialoglycoprotein receptor. FEBS Lett. 296: 174-178

8. Moffatt OD, Devitt A, Bell ED, Simmons DL and Gregory CD (1999) Macrophage recognition of ICAM-3 on apoptotic leukocytes. J. Immunol. 162: $6800-6810$

9. Brown S, Heinisch I, Ross E, Shaw K, Buckley CD and Savill J (2002) Apoptosis disables CD31-mediated cell detachment from phagocytes promoting binding and engulfment. Nature 418: 200-203

10. Devitt A, Moffatt OD, Raykundalia C, Capra JD, Simmons DL and Gregory CD (1998) Human CD14 mediates recognition and phagocytosis of apoptotic cells. Nature 392: 505-509

11. Fadok VA, Bratton DL, Rose DM, Pearson A, Ezekewitz RAB and Henson PM (2000) A receptor for phosphatidylserine-specific clearance of apoptotic cells. Nature 405: 85-90

12. Savill J, Dransfield I, Hogg N and Haslett C (1990) Vitronectin receptor-mediated phagocytosis of cells undergoing apoptosis. Nature 343 : 170-173

13. Savill J, Hogg N, Ren Y and Haslett C (1992) Thrombospondin cooperates with CD36 and the vitronectin receptor in macrophage recognition of neutrophils undergoing apoptosis. J. Clin. Invest. 90: 1513-1522

14. Ren Y, Silverstein RL, Allen J and Savill J (1995) CD36 gene transfer confers capacity for phagocytosis of cells undergoing apoptosis. J. Exp. Med. 181: 1857-1862

15. Platt N, Suzuki H, Kurihara Y, Kodama T and Gordon S (1996) Role for the class A macrophage scavenger receptor in the phagocytosis of apoptotic thymocytes in vitro. Proc. Natl. Acad. Sci. USA 93: 12456-12460

16. Luciani M-F and Chimini G (1996) The ATP binding cassette transporter ABC1, is required for the engulfment of corpses generated by apoptotic cell death. EMBO J. 15: 226-235

17. Hamon $Y$, Broccardo C, Chambenoit O, Luciani MF, Toti F, Chaslin S, Freyssinet JM, Devaux PF, McNeish J, Marguet D and Chimini G (2000) ABC1 promotes engulfment of apoptotic cells and transbilayer redistribution of phosphatidylserine. Nat. Cell Biol. 2: 399-406

18. Scott RS, McMahon EJ, Pop SM, Reap EA, Caricchio R, Cohen PL, Earp HS and Matsushima GK (2001) Phagocytosis and clearance of apoptotic cells is mediated by MER. Nature 411: 207-211

19. Ogden CA, deCathelineau A, Hoffmann PR, Bratton D, Ghebrehiwet B, Fadok VA and Henson PM (2001) C1q and mannose-binding lectin engagement of cell surface calreticulin and CD91 initiates macropinocytosis and uptake of apoptotic cells. J. Exp. Med. 194: 781-795

20. Botto M, DellAgnola C, Bygrave AE, Thompson EM, Cook HT, Petry F, Loos M, Pandolfi PP and Walport MJ (1998) Homozygous C1q deficiency causes glomerulonephritis associated with multiple apoptotic bodies. Nat. Genet. 19: 56-59

21. Gershov D, Kim S, Brot N and Elkon KB (2000) C-reactive protein binds to apoptotic cells, protects the cells from assembly of the terminal complement components, and sustains an antiinflammatory innate immune response: implications for systemic autoimmunity. J. Exp. Med. 192: 1353-1363

22. Schagat TL, Wofford JA and Wright JR (2001) Surfactant protein A enhances alveolar macrophage phagocytosis of apoptotic neutrophils. J. Immunol. 166: 2727-2733

23. Hoffmann PR, deCathelineau AM, Ogden CA, Leverrier Y, Bratton DL, Daleke DL, Ridley AJ, Fadok VA and Henson PM (2001) Phosphatidylserine (PS) induces PS receptor-mediated macropinocytosis and promotes clearance of apoptotic cells. J. Cell Biol. 155: 649-659

24. Flora PK and Gregory CD (1994) Recognition of apoptotic cells by human macrophages - inhibition by a monocyte/macrophage-specific monoclonal antibody. Eur. J. Immunol. 24: 2625-2632

25. Schlegel RA, Krahling S, Callahan MK and Williamson P (1999) CD14 is a component of multiple recognition systems used by macrophages to phagocytose apoptotic lymphocytes. Cell Death Differ. 6: 583-592 
26. Yu B, Hailman E and Wright SD (1997) Lipopolysaccharide binding protein and soluble CD14 catalyze exchange of phospholipids. J. Clin. Invest. 99: 315-324

27. Wang PY, Kitchens RL and Munford RS (1998) Phosphatidylinositides bind to plasma membrane CD14 and can prevent monocyte activation by bacterial lipopolysaccharide. J. Biol. Chem. 273: 24309-24313

28. Wang PY and Munford RS (1999) CD14-dependent internalization and metabolism of extracellular phosphatidylinositol by monocytes. J. Biol. Chem. 274: 23235-23241

29. Sugiyama $T$ and Wright SD (2001) Soluble CD14 mediates efflux of phospholipids from cells. J. Immunol. 166: 826-831

30. Haslett C, Guthrie LA, Kopaniak MM, Johnston RB and Henson PM (1985) Modulation of multiple neutrophil functions by preparative methods or trace concentrations of bacterial lipopolysaccharide. Am. J. Pathol. 119: $101-110$

31. Gregory CD, Rowe M and Rickinson AB (1990) Different Epstein-Barr virus-B cell interactions in phenotypically distinct clones of a Burkitt's lymphoma cell line. J. General Virol. 71: 1481-1495

32. Visvader JE, Elefanty AG, Strasser A and Adams JM (1992) GATA-1 but not $S C L$ induces megakaryocytic differentiation in an early myeloid line. EMBO J. 11: $4557-4564$

33. Fadok VA, Warner ML, Bratton DL and Henson PM (1998) CD36 is required for phagocytosis of apoptotic cells by human macrophages that use either a phosphatidylserine receptor or the vitronectin receptor (alpha(v)beta(3)). J. Immunol. 161: 6250-6257

34. Schlegel RA and Rechsteiner MC (1978) Red cell-mediated microinjection of macromolecules into mammalian cells. Methods Cell Biol. 20: 341-354

35. Fadok VA, Savill JS, Haslett C, Bratton DL, Doherty DE, Campbell PA and Henson PM (1992) Different populations of macrophages use either the vitronectin receptor or the phosphatidylserine receptor to recognize and remove apoptotic cells. J. Immunol. 149: 4029-4035

36. Gregory CD and Devitt A (1999) CD14 and apoptosis. Apoptosis 4: 11-20

37. Dziarski R, Ulmer AJ and Gupta D (2000) Interactions of CD14 with components of Gram-positive bacteria. In CD14 in the Inflammatory Response pp. 83-107 RS Jack (ed) Karger

38. Kitchens RL (2000) Role of CD14 in cellular recognition of bacterial lipopolysaccharides. In CD14 in the Inflammatory Response pp. 61-82 RS Jack (ed) Karger

39. Janicke RU, Sprengart ML, Wati MR and Porter AG (1998) Caspase-3 is required for DNA fragmentation and morphological changes associated with apoptosis. J. Biol. Chem. 273: 9357-9360

40. Woo M, Hakem R, Soengas MS, Duncan GS, Shahinian A, Kagi D, Hakem A, McCurrach M, Khoo W, Kaufman SA, Senaldi G, Howard T, Lowe SW and Mak
TW (1998) Essential contribution of caspase 3 CPP32 to apoptosis and its associated nuclear changes. Genes Dev. 12: 806-819

41. Zheng TS, Schlosser SF, Dao T, Hingorani R, Crispe IN, Boyer JL and Flavell RA (1998) Caspase-3 controls both cytoplasmic and nuclear events associated with Fas-mediated apoptosis in vivo. Proc. Natl. Acad. Sci. USA 95: 1361813623

42. Turner C, Devitt A, Parker K, MacFarlane M, Giuliano M, Cohen GM and Gregory CD (2002) Macrophage-mediated clearance of cells undergoing caspase-3-independent death. Submitted

43. Krahling S, Callahan MK, Williamson P and Schlegel RA (1999) Exposure of phosphatidylserine is a general feature in the phagocytosis of apoptotic lymphocytes by macrophages. Cell Death Differ. 6: 183-189

44. Shiratsuchi A, Osada S, Kanazawa S and Nakanishi Y (1998) Essential role of phosphatidylserine externalization in apoptosing cell phagocytosis by macrophages. Biochem. Biophys. Res. Comm. 246: 549-555

45. Verhoven B, Krahling S, Schlegel RA and Williamson P (1999) Regulation of phosphatidylserine exposure and phagocytosis of apoptotic $T$ lymphocytes. Cell Death Differ. 6: 262-270

46. Kagan VE, Gleiss B, Tyurina YY, Tyurin VA, Elenstrom-Magnusson C, Liu SX, Serinkhan FB, Arroyo A, Chandra J, Orrenius S and Fadeel B (2002) A role for oxidative stress in apoptosis: oxidation and externalization of phosphatidylserine is required for macrophage clearance of cells undergoing Fas-mediated apoptosis. J. Immunol. 169: 487-499

47. Dillon SR, Mancini M, Rosen A and Schlissel MS (2000) Annexin V binds to viable $B$ cells and colocalizes with a marker of lipid rafts upon $B$ cell receptor activation. J. Immunol. 164: 1322-1332

48. Dini L, Carla EC, De Luca M, Faraldi G and Tagliafierro G (1999) Phagocytosis of apoptotic cells: liver recognition and molecular mechanisms. Italian J. Zool. 66: 317-322

49. Watanabe Y, Shiratsuchi A, Shimizu K, Takizawa T and Nakanishi Y (2002) Role of phosphatidylserine exposure and sugar chain desialylation at the surface of influenza virus-infected cells in efficient phagocytosis by macrophages. J. Biol. Chem. 277: 18222-18228

50. Fujii C, Shiratsuchi A, Manaka J, Yonehara S and Nakanishi Y (2001) Difference in the way of macrophage recognition of target cells depending on their apoptotic states. Cell Death Differ. 8: 1113-1122

51. Anderson HA, Englert R, Gursel I and Shacter E (2002) Oxidative stress inhibits the phagocytosis of apoptotic cells that have externalized phosphatidylserine. Cell Death Differ. 9: 616-625

52. Ren Y, Stuart L, Lindberg FP, Rosenkranz AR, Chen YM, Mayadas TN and Savill J (2001) Non-phlogistic clearance of late apoptotic neutrophils by macrophages: efficient phagocytosis independent of beta(2) integrins. $J$. Immunol. 166: 4743-4750 